\title{
Pasireotide LAR maintains inhibition of GH and IGF-1 in patients with acromegaly for up to 25 months: results from the blinded extension phase of a randomized, double-blind, multicenter, Phase III study
}

\author{
Michael Sheppard • Marcello D. Bronstein • Pamela Freda • Omar Serri • \\ Laura De Marinis • Luciana Naves • Liudmila Rozhinskaya • Karina Hermosillo Reséndiz • \\ Matthieu Ruffin • YinMiao Chen • Annamaria Colao
}

Published online: 8 August 2014

(C) The Author(s) 2014. This article is published with open access at Springerlink.com

\begin{abstract}
Purpose A large, randomized, double-blind, Phase III core study demonstrated that pasireotide LAR was significantly superior to octreotide LAR at providing $\mathrm{GH}<2.5 \mu \mathrm{g} / \mathrm{L}$ and normalized IGF-1 after 12 months' treatment in patients with acromegaly. We report the efficacy and safety of pasireotide LAR and octreotide LAR after up to 26 months' treatment.

Methods Patients with $\mathrm{GH}<2.5 \mu \mathrm{g} / \mathrm{L}$ and IGF$1 \leq 1 \times$ ULN at month 12 , or patients considered to be experiencing clinical benefit, were eligible to continue
\end{abstract}

On behalf of the Pasireotide C2305 Study Group.

Electronic supplementary material The online version of this article (doi:10.1007/s11102-014-0585-6) contains supplementary material, which is available to authorized users.

\section{Sheppard ( $\square)$}

Centre for Endocrinology, Diabetes and Metabolism, University of Birmingham, Edgbaston, Birmingham B15 2TT, UK

e-mail: m.c.sheppard@bham.ac.uk

\section{D. Bronstein}

Neuroendocrine Unit, Division of Endocrinology and

Metabolism, University of São Paulo Medical School,

São Paulo, Brazil

P. Freda

Department of Medicine, Columbia University College of

Physicians and Surgeons, New York, NY, USA

O. Serri

Service of Endocrinology, Centre Hospitalier de l'Université de Montréal, Notre-Dame Hospital, University of Montreal,

Montreal, Canada

L. De Marinis

Section of Endocrinology, Department of Internal Medicine,

Università Cattolica del Sacro Cuore, Rome, Italy receiving their randomized therapy in the extension. Efficacy and safety in the pasireotide LAR and octreotide LAR groups were evaluated for up to 26 months.

Results Overall, 120 patients who completed the core study continued receiving pasireotide LAR $(n=74)$ or octreotide LAR $(\mathrm{n}=46)$ in the extension. At month 25 , biochemical control ( $\mathrm{GH}<2.5 \mu \mathrm{g} / \mathrm{L}$ and normal IGF-1) was achieved by $48.6 \%(36 / 74)$ and $45.7 \%(21 / 46)$ of patients in the pasireotide LAR and octreotide LAR arms [60.8\% (45/74) and $52.2 \%(24 / 46)$ when including patients with IGF-1 < LLN], respectively. In total, $74.7 \%$ of pasireotide LAR and $71.6 \%$ of octreotide LAR patients had tumor volume decrease $\geq 20 \%$ from baseline to month 26. Most AEs were mild or moderate. Hyperglycemiarelated AEs were seen in 62.9 and $25.0 \%$ of pasireotide LAR and octreotide LAR patients, respectively. No new

L. Naves

Unit of Endocrinology, Department of Internal Medicine,

University of Brasilia, Brasilia, Brazil

L. Rozhinskaya

Endocrinology Research Center, Moscow, Russia

K. Hermosillo Reséndiz

Clinical Development, Novartis Pharmaceuticals Corporation,

Florham Park, NJ, USA

M. Ruffin

Clinical Development, Oncology Business Unit, Novartis Pharma AG, Basel, Switzerland

Y. Chen

Novartis Pharmaceuticals Corporation, East Hanover, NJ, USA

A. Colao

Dipartimento di Medicina Clinica e Chirurgia, Università

Federico II di Napoli, Naples, Italy 
safety signals were observed in the extension compared with the core study.

Conclusions $\mathrm{GH}$ and IGF-1 suppression is maintained for up to 25 months during pasireotide LAR treatment. The safety profile of pasireotide LAR is typical of a somatostatin analogue, except for the frequency and degree of hyperglycemia.

\section{Keywords Pasireotide - Octreotide · Acromegaly · Extension}

\section{Introduction}

Acromegaly is characterized by chronic hypersecretion of growth hormone $(\mathrm{GH})$, which primarily originates from a GH-secreting pituitary adenoma and induces the synthesis of insulin-like growth factor 1 (IGF-1). Elevated GH and IGF-1 levels cause metabolic dysfunction and somatic growth, resulting in significant morbidity and mortality for patients with acromegaly. As decreasing $\mathrm{GH}$ to $<2.5 \mu \mathrm{g} / \mathrm{L}$ and IGF-1 to normal levels significantly reduces mortality [1-4], the main treatment goal for acromegaly is to control $\mathrm{GH}$ and IGF-1 levels. Additional goals are to reduce and/or stabilize tumor size, preserve pituitary function and prevent recurrence [5].

Long-acting somatostatin analogues are the cornerstone of medical therapy for acromegaly and are indicated in patients with failed surgery or as first-line treatment when surgery is contraindicated or declined $[6,7]$. Various studies have demonstrated that somatostatin analogues can be effective as both first- and second-line therapy over longterm treatment [8-13]. In selected patients with active acromegaly, long-term somatostatin analogue therapy has been demonstrated to effectively control GH and IGF-1 levels, induce tumor volume reduction and improve hypertension and cardiac performance $[9,10,12]$. However, many patients with acromegaly do not achieve biochemical control with the currently available somatostatin analogues [14].

Pasireotide has a broader somatostatin receptor (sst) binding profile than the currently available somatostatin analogues. Pasireotide has 30-, 5- and 39-fold higher binding affinity for $\mathrm{sst}_{1}, \mathrm{sst}_{3}$ and $\mathrm{sst}_{5}$, respectively, than octreotide, and a slightly lower affinity for $\mathrm{sst}_{2}$ [15]. As demonstrated previously, pasireotide has the potential to be an effective medical therapy for patients with acromegaly $[16,17]$. In a large, randomized, 12-month, Phase III core study in medically naïve patients with acromegaly, pasireotide long-acting release (LAR) was significantly superior $(P=0.007)$ to octreotide LAR at providing $\mathrm{GH}<2.5 \mu \mathrm{g} / \mathrm{L}$ and normal IGF-1 [16]. Patients who completed this core study and had $\mathrm{GH}<2.5 \mu \mathrm{g} / \mathrm{L}$ and IGF$1 \leq 1 \times$ the upper limit of normal (ULN) at month 12 , or who were considered by the investigator to be receiving clinical benefit (irrespective of biochemical control), were able to continue on their randomized therapy in a planned extension study. Here we report the efficacy and safety of pasireotide LAR and octreotide LAR after up to 26 months' treatment in these patients.

\section{Methods}

Study design and patient population

This was a double-blind extension to a multicenter, 12-month, Phase III core study enrolling medically naïve patients with active acromegaly who either had prior pituitary surgery or were de novo with a visible pituitary adenoma on magnetic resonance imaging (MRI) [16]. In the 12-month core study, patients were randomized to pasireotide LAR $40 \mathrm{mg}$ every 28 days $(\mathrm{n}=176)$ or octreotide LAR $20 \mathrm{mg}$ every 28 days $(\mathrm{n}=182)$ [16]. A dose increase to pasireotide LAR $60 \mathrm{mg}$ or octreotide LAR $30 \mathrm{mg}$ was permitted, but not mandatory, at month 3 or 7 based on biochemical response (mean $\mathrm{GH} \geq 2.5 \mu \mathrm{g} / \mathrm{L}$ and/ or IGF-1 $>1 \times$ ULN). Dose decreases (pasireotide LAR: from 60 to $40 \mathrm{mg}$ or from 40 to $20 \mathrm{mg}$; octreotide LAR: from 30 to $20 \mathrm{mg}$ or from 20 to $10 \mathrm{mg}$ ) were permitted for tolerability, as was an increase to the original dose upon resolution. A detailed description of the methods and dosing employed in the core study has been published [16].

In the extension phase, patients with $\mathrm{GH}<2.5 \mu \mathrm{g} / \mathrm{L}$ and IGF- $1 \leq 1 \times$ ULN at month 12 , or those patients considered by the investigator to be experiencing clinical benefit from the study drug, were eligible to continue receiving their randomized therapy (Fig. 1). Patients with $\mathrm{GH} \geq 2.5 \mu \mathrm{g} / \mathrm{L}$ and/or IGF-1 $>1 \times$ ULN could switch treatment to either pasireotide LAR $40 \mathrm{mg}$ every 28 days or octreotide LAR $20 \mathrm{mg}$ every 28 days at month 13; results from these patients are not reported here and will be described in a separate manuscript. Patients continuing on their randomized therapy received the same pasireotide LAR or octreotide LAR dose in the extension phase that they were receiving at the end of the core study. A dose increase was permitted at any time during the extension when $\mathrm{GH}$ levels were $\geq 2.5 \mu \mathrm{g} / \mathrm{L}$ and/or IGF-1 $>1 \times \mathrm{ULN}$; maximum permitted doses of pasireotide LAR and octreotide LAR were 60 and $30 \mathrm{mg}$ every 28 days, respectively. Dose decreases as with the core study were permitted at any time in the event of tolerability issues; the dose could be increased to the original dose upon resolution.

Thirty-four patients entered the extension phase before a protocol amendment was implemented; these patients received unblinded pasireotide LAR treatment during the extension. Of these patients, 15 received pasireotide LAR 

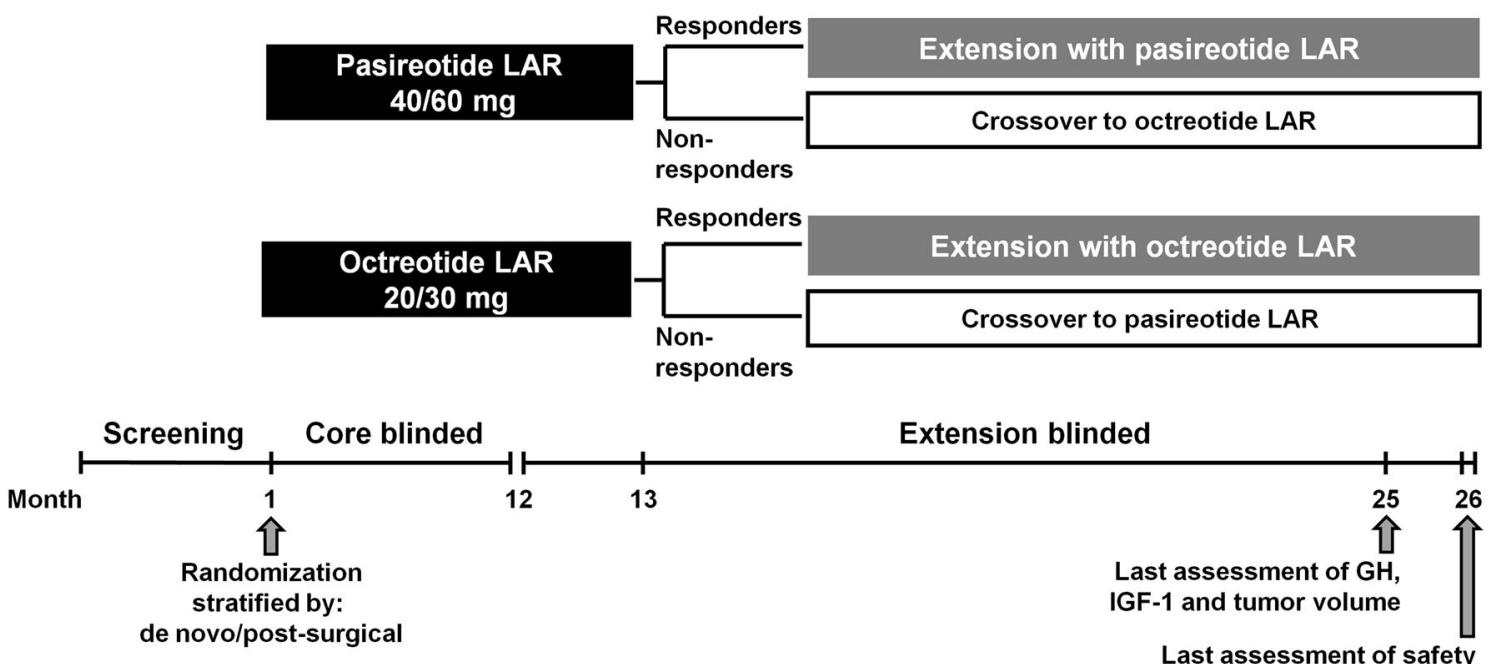

Extension blinded
Last assessment of GH,
IGF-1 and tumor volume
Last assessment of safety and symptom score

Fig. 1 Study design

and 19 received octreotide LAR during the core study. Prior to the protocol amendment, patients randomized to octreotide LAR who achieved $\mathrm{GH}<2.5 \mu \mathrm{g} / \mathrm{L}$ and IGF$1 \leq 1 \times \mathrm{ULN}$ at month 12 could not continue receiving octreotide LAR during the extension phase; these patients were considered to have completed the study and were discontinued. Additionally, patients randomized to pasireotide LAR did not have the option to switch to octreotide LAR at month 13 if $\mathrm{GH}$ was $\geq 2.5 \mu \mathrm{g} / \mathrm{L}$ and/or IGF$1>1 \times$ ULN. Following the protocol amendment, patients in both treatment arms who had $\mathrm{GH}<2.5 \mu \mathrm{g} / \mathrm{L}$ and IGF$1 \leq 1 \times$ ULN or were considered by the investigator to be achieving drug-related clinical benefit at month 12 could continue on their randomized therapy, and patients in both treatment arms could switch therapies at month 13. Patients who entered the extension phase after the protocol amendment was implemented received treatment in a double-blind manner up to month 26 . Nineteen patients in the pasireotide LAR arm and 13 patients in the octreotide LAR arm completed the core study prior to the protocol amendment but did not enter the extension phase. Based on manual review of the response status for these patients at month 12 , it is estimated that four patients in the octreotide LAR arm would have potentially been eligible to continue receiving octreotide LAR during the extension phase had they reached the end of the core study after the protocol amendment was implemented; 14 patients in the pasireotide LAR arm would have potentially been eligible to cross over to octreotide LAR treatment during the extension phase.

The study was conducted in accordance with the Declaration of Helsinki, and an independent ethics committee or institutional review board for each study site approved the study protocol. All patients provided written informed consent to participate in the trial. The ClinicalTrials.gov identifier is NCT00600886.

Endpoints and assessments

The key efficacy endpoint assessed was the proportion of patients who achieved biochemical control, defined as $\mathrm{GH}<2.5 \mu \mathrm{g} / \mathrm{L}$ (mean $\mathrm{GH}$ concentration of a five-point profile within a 2-hour time period) and normal IGF-1 (according to age and sex), at the end of the blinded extension phase. Additional efficacy endpoints were the proportion of patients achieving $\mathrm{GH}<2.5 \mu \mathrm{g} / \mathrm{L}$ and IGF$1 \leq 1 \times$ ULN (i.e. including patients who had IGF-1 levels below the lower limit of normal [LLN]), the proportion achieving $\mathrm{GH}<2.5 \mu \mathrm{g} / \mathrm{L}$, the proportion achieving normal IGF-1, and overall changes in GH and IGF-1 levels. All $\mathrm{GH}$ and IGF-1 samples were measured using validated chemiluminescent immunometric assays $\left[\right.$ Immulite ${ }^{\circledR}$ 2000/1000; Diagnostic Products Corp (Siemens), Los Angeles, CA; GH International Reference Preparation (IRP) WHO NIBSC 2nd IS 98/574; IGF-1 IRP WHO NIBSC 1st IRR 87/518]. The lower limit of detection for $\mathrm{GH}$ was $0.1 \mu \mathrm{g} / \mathrm{L}$, with intra- and inter-assay coefficients of variation $\leq 6.6 \%$. For IGF-1, the lower limit of detection was $20 \mu \mathrm{g} / \mathrm{L}$, with intra- and inter-assay coefficients of variation $\leq 6.7 \%$. IGF-1 values were compared with ageand sex-standardized normal values. All samples except for those from China were analyzed using the Immulite ${ }^{\circledR} 2000$ assay by Quest Diagnostics Nichols Institute Laboratory, San Juan Capistrano, California, USA between March 2008 and March 2010, then by Quest Diagnostics Clinical Trials Laboratory, Valencia, California, USA from March 2010 
onwards. Samples from China were analyzed using the Immulite ${ }^{\circledR} 1000$ assay by Kingmed Diagnostics, Guangzhou, China. Subsequent to receiving a notification from Siemens regarding the Immulite ${ }^{\circledR}$ IGF-1 assay, Quest Diagnostics reviewed all quality control data collected from the three laboratories and verified that all IGF-1 data are valid.

Tumor volume was evaluated every 6 months by gadolinium-enhanced pituitary MRI performed by a central reader blinded to treatment. A pituitary tumor volume change of $\geq 20 \%$ from screening was considered significant. Tumor volume was calculated by hand-drawing around the tumor circumference in coronal cross-sections, multiplying the area by slice thickness, and summing the resulting volumes across all slices containing tumor. As the last assessment of GH, IGF-1 and tumor volume prior to the end of the planned blinded extension phase was performed at month 25, these data are reported up to month 25. Changes in five signs and symptoms of acromegaly (headache, fatigue, perspiration, paresthesia and osteoarthralgia) were evaluated monthly and scored from 0 (no symptom) to 4 (very severe); data are presented up to month 26. See the Supplementary Appendix for further details.

Safety was assessed based on the monitoring and recording of all adverse events (AEs), evaluated according to the National Cancer Institute Common Terminology Criteria for AEs version 3.0 [18], as well as regular monitoring of hematology, blood chemistry and urinalysis parameters, performance of physical examinations and electrocardiograms, and body weight measurements. Blood samples for laboratory tests, including blood glucose measurements, were drawn at each visit under fasted conditions before the morning dose of study drug. Safety data are presented for all patients in the core study (i.e. up to month 12) and all patients who continued on their randomized therapy in the extension phase (i.e. months 12-26). Extension-phase data from patients who switched treatments at the end of the core study are not included and will be published separately.

\section{Statistical analyses}

This analysis focuses on data from patients who continued on their randomized therapy in the extension phase. If $<3$ $\mathrm{GH}$ samples were taken for the assessment of mean $\mathrm{GH}$ (based on a five-point 2-hour profile), the value was considered to be missing at the corresponding visit. If $\mathrm{GH}$ and IGF-1 assessments were taken $>35$ days after the pasireotide LAR or octreotide LAR injection, these values were also considered to be missing at the corresponding visit. The calculation of the proportion of patients who achieved $\mathrm{GH}<2.5 \mu \mathrm{g} / \mathrm{L}$ and normal IGF-1 during the extension phase was performed without the imputation of missing values. Patients who discontinued treatment were considered to be non-responders at later time points. If one of the two biochemical values (mean GH or IGF-1) was missing, and if the available value did not meet the response criteria for the given parameter, the patient was considered to be a non-responder at that visit; if the available value met the response criteria set for the given biochemical parameter, the patient's response status was considered missing. Descriptive statistics for quantitative variables (i.e. $\mathrm{GH}$, IGF-1, tumor volume, signs and symptoms scores) were based on available measurements. No formal statistical analyses were planned to compare the pasireotide LAR and octreotide LAR treatment arms during the extension phase. In addition, the extension phase was not powered to determine a difference in efficacy or safety outcomes between the two treatment arms. For the purposes of this analysis, changes in patient diabetic status were calculated according to current American Diabetes Association (ADA) criteria for normal glucose tolerance [glycated hemoglobin $\left(\mathrm{HbA}_{1 \mathrm{c}}\right)<5.7 \%$ ], pre-diabetes $\left(\mathrm{HbA}_{1 \mathrm{c}} \geq 5.7\right.$ to $<6.5 \%)$ and diabetes $\left(\mathrm{HbA}_{1 \mathrm{c}} \geq 6.5 \%\right)$.

\section{Results}

\section{Patient population}

In total, $141 / 176(80.1 \%)$ and 156/182 (85.7\%) patients in the pasireotide LAR and octreotide LAR arms, respectively, completed the 12-month core study. Of those patients who completed the core study, 74 pasireotide LAR patients and 46 octreotide LAR patients continued on their randomized therapy in the extension phase (Table 1; Fig. 2). The mean duration of exposure to study treatment was 527 days (1.4 years) in the pasireotide LAR arm and 415 days (1.1 years) in the octreotide LAR arm.

\section{Effect of treatment on GH and IGF-1 levels}

Of the patients who continued receiving their randomized treatment in the extension phase, 53/74 (71.6\%) in the pasireotide LAR arm and 26/46 (56.5\%) in the octreotide LAR arm had $\mathrm{GH}<2.5 \mu \mathrm{g} / \mathrm{L}$ and $\mathrm{IGF}-1 \leq 1 \times \mathrm{ULN}$ at entry into the extension phase. The remainder were judged by the investigator to have been receiving clinical benefit from treatment. Of these patients, seven in the pasireotide LAR arm and 11 in the octreotide LAR arm were partial responders (defined as $\mathrm{GH}<5 \mu \mathrm{g} / \mathrm{L}$ and $\mathrm{IGF}-1 \leq 1.3 \times \mathrm{ULN}$, but not biochemical control), while 13 and eight patients, respectively, were non-responders (defined as neither a responder nor a partial responder), at entry into the extension phase. This information was missing from one patient in each group. 
Table 1 Patient demographics and characteristics at core baseline for patients who continued on their randomized therapy in the extension phase

\begin{tabular}{lll}
\hline Demographic variable & $\begin{array}{l}\text { Pasireotide LAR } \\
(\mathrm{n}=74)\end{array}$ & $\begin{array}{l}\text { Octreotide LAR } \\
(\mathrm{n}=46)\end{array}$ \\
\hline Age, years & $n=74$ & $n=46$ \\
Median (range) & $46.5(22-71)$ & $45.0(24-70)$ \\
Sex, n (\%) & & \\
Female & $38(51.4)$ & $26(56.5)$ \\
Male & $36(48.6)$ & $20(43.5)$ \\
Race, n (\%) & & \\
Caucasian & $41(55.4)$ & $28(60.9)$ \\
Black & 0 & $1(2.2)$ \\
Asian & $21(28.4)$ & $9(19.6)$ \\
Native American & $3(4.1)$ & 0 \\
Other & $9(12.2)$ & $8(17.4)$ \\
Previous surgery, n $(\%)$ & $37(50.0)$ & $20(43.5)$ \\
GH level, $\mu$ g/L & $n=70$ & $n=45$ \\
Mean (SD) & $14.4(21.4)$ & $11.3(12.7)$ \\
Median (range) & $6.9(0.8-114.6)$ & $6.5(1.4-64.1)$ \\
IGF-1 level, $\times$ ULN & $n=74$ & $n=46$ \\
Mean (SD) & $2.6(1.2)$ & $2.5(1.1)$ \\
Median (range) & $2.4(0.9-5.9)$ & $2.4(0.9-6.5)$ \\
Tumor volume, mm ${ }^{3}$ & $n=71$ & $n=43$ \\
Mean (SD) & $1,981(4,515)$ & $2,429(4,936)$ \\
Median (range) & $646(0-35,095)$ & $772(53-25,473)$ \\
\hline & &
\end{tabular}

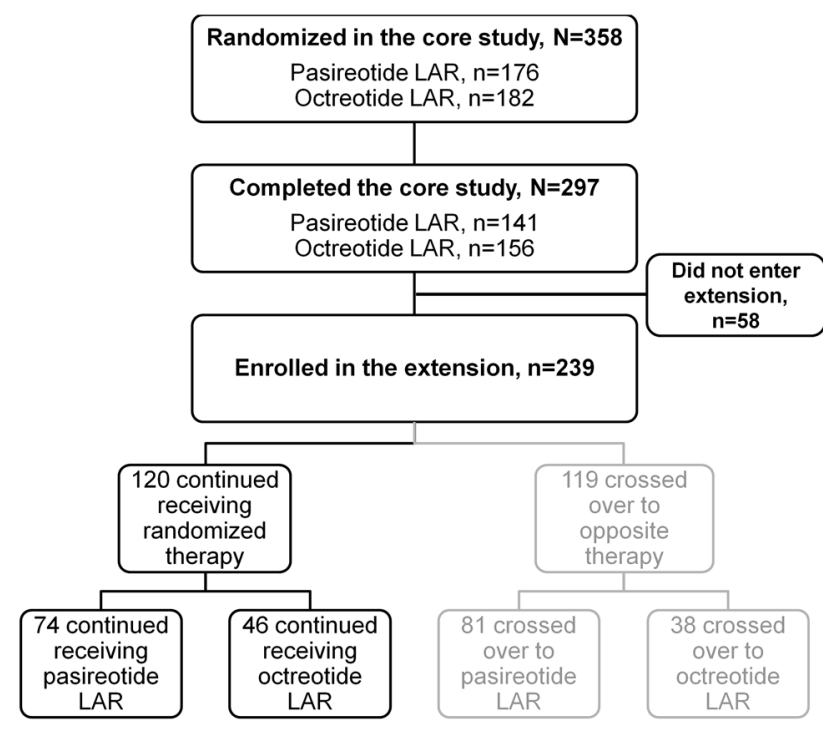

Fig. 2 Flowchart showing the number of patients who were randomized, completed the 12-month core study and entered the extension phase

At month 25, 36/74 (48.6\%) pasireotide LAR and 21/46 (45.7\%) octreotide LAR patients had biochemical control $(\mathrm{GH}<2.5 \mu \mathrm{g} / \mathrm{L}$ and normal IGF-1), while 45/74 (60.8\%) and 24/46 (52.2\%) had mean $\mathrm{GH}<2.5 \mu \mathrm{g} / \mathrm{L}$ and IGF$1 \leq 1 \times$ ULN (Table 2). The proportion of patients with a reduction in mean $\mathrm{GH}$ to $<2.5 \mu \mathrm{g} / \mathrm{L}$ at the end of the extension phase was $70.3 \%(\mathrm{n}=52 / 74)$ for the pasireotide LAR and $80.4 \%(\mathrm{n}=37 / 46)$ for the octreotide LAR arms (Table 2). Overall, $51.4 \%$ (38/74) and $47.8 \%$ (22/ 46) of patients in the pasireotide LAR and octreotide LAR arms, respectively, had normal IGF-1 at the end of the extension (Table 2). Median GH levels were $<2.5 \mu \mathrm{g} / \mathrm{L}$ by month 3 in the pasireotide LAR arm and by month 6 in the octreotide LAR arm and remained below this threshold up to month 25. Median IGF-1 levels were within the normal range by month 6 in the pasireotide LAR arm and month 16 in the octreotide LAR arm and remained so at month 25 (Fig. 3).

\section{Tumor response}

The mean decrease from core baseline to the end of the blinded extension phase was $600 \pm 735 \mathrm{~mm}^{3}(51.8 \%$ decrease) and $1,120 \pm 2,541 \mathrm{~mm}^{3}(55.0 \%$ decrease $)$ in the pasireotide LAR and octreotide LAR arms, respectively. The proportion of patients who achieved a significant reduction in tumor volume of $\geq 20 \%$ at the end of the blinded extension phase was similar in both treatment groups $(74.7 \%$ for pasireotide LAR and $71.6 \%$ for octreotide LAR); the median time to significant tumor volume reduction was 25.0 weeks for pasireotide LAR and 24.3 weeks for octreotide LAR.

Effect on signs and symptoms of acromegaly

The five assessed symptoms of acromegaly improved from core baseline in both treatment groups. By month 26, decreases in mean symptom scores from core baseline were seen in the pasireotide LAR and octreotide LAR arms for headache $(0.0 \pm 0.9$ and $0.2 \pm 0.9)$, fatigue $(0.4 \pm 1.4$ and $0.4 \pm 1.4)$, perspiration $(0.0 \pm 0.7$ and $1.0 \pm 1.2)$, osteoarthralgia $(0.3 \pm 1.2$ and $0.2 \pm 1.3)$, and paresthesia $(0.2 \pm 0.6$ and $0.3 \pm 0.8)$.

Safety and tolerability during core and extension

Overall, 23/74 (31.1\%) and 10/46 (21.7\%) patients in the pasireotide LAR and octreotide LAR arms who continued receiving their randomized treatment in the extension phase discontinued treatment between months 12 and 26 . Of these, 11/23 (47.8\%) patients in the pasireotide LAR arm and 3/10 (30.0\%) patients in the octreotide LAR arm had $\mathrm{GH}<2.5 \mu \mathrm{g} / \mathrm{L}$ and IGF-1 $\leq 1 \times \mathrm{ULN}$ at last assessment. The most common reason for discontinuation during the blinded extension phase was consent withdrawal (12.2 and $4.3 \%$ in the pasireotide LAR and octreotide LAR 
Table 2 Biochemical response rates

Patients who discontinued treatment during the extension phase were considered to be non-responders at subsequent time points

\begin{tabular}{|c|c|c|c|c|}
\hline & \multicolumn{2}{|c|}{ Pasireotide LAR $(\mathrm{n}=74)$} & \multicolumn{2}{|c|}{ Octreotide LAR (n=46) } \\
\hline & $\mathrm{n} / \mathrm{N}(\%)$ & $95 \% \mathrm{CI}$ & $\mathrm{n} / \mathrm{N}(\%)$ & $95 \%$ CI \\
\hline \multicolumn{5}{|c|}{$\mathrm{GH}<2.5 \mu \mathrm{g} / \mathrm{L}$ and $\mathrm{IGF}-1$ normalization } \\
\hline Month 12 & $46 / 74(62.2)$ & $50.1,73.2$ & $24 / 46(52.2)$ & $36.9,67.1$ \\
\hline Month 19 & $34 / 74(45.9)$ & $34.3,57.9$ & $21 / 46(45.7)$ & $30.9,61.0$ \\
\hline Month 25 & $36 / 74(48.6)$ & $36.9,60.6$ & $21 / 46(45.7)$ & $30.9,61.0$ \\
\hline \multicolumn{5}{|c|}{$\mathrm{GH}<2.5 \mu \mathrm{g} / \mathrm{L}$ and $\mathrm{IGF}-1 \leq 1 \times \mathrm{ULN}$} \\
\hline Month 12 & $53 / 74(71.6)$ & $59.9,81.5$ & $26 / 46(56.5)$ & $41.1,71.1$ \\
\hline Month 19 & $44 / 74(59.5)$ & $47.4,70.7$ & $23 / 46(50.0)$ & $34.9,65.1$ \\
\hline Month 25 & $45 / 74(60.8)$ & $48.8,72.0$ & $24 / 46(52.2)$ & $36.9,67.1$ \\
\hline \multicolumn{5}{|c|}{$\mathrm{GH}<2.5 \mu \mathrm{g} / \mathrm{L}$} \\
\hline Month 12 & $58 / 74(78.4)$ & $67.3,87.1$ & $37 / 46(80.4)$ & $66.1,90.6$ \\
\hline Month 19 & $54 / 74(73.0)$ & $61.4,82.6$ & $33 / 46(71.7)$ & $56.5,84.0$ \\
\hline Month 25 & $52 / 74(70.3)$ & $58.5,80.3$ & $37 / 46(80.4)$ & $66.1,90.6$ \\
\hline \multicolumn{5}{|c|}{ IGF-1 normalization } \\
\hline Month 12 & $55 / 74(74.3)$ & $62.8,83.8$ & $26 / 46(56.5)$ & $41.1,71.1$ \\
\hline Month 19 & $37 / 74(50.0)$ & $38.1,61.9$ & $24 / 46(52.2)$ & $36.9,67.1$ \\
\hline Month 25 & 38/74 (51.4) & $39.4,63.1$ & $22 / 46(47.8)$ & $32.9,63.1$ \\
\hline
\end{tabular}
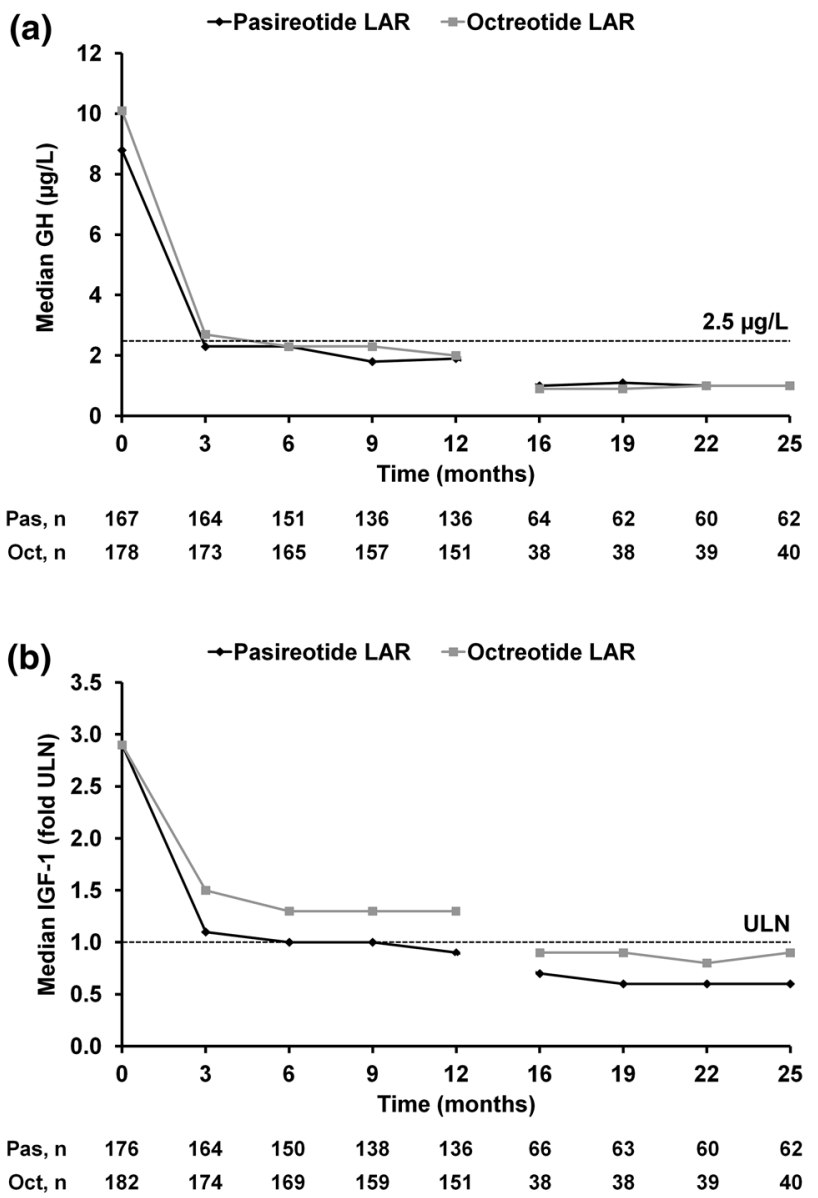

Fig. 3 Median a GH and b IGF-1 levels during treatment. The total numbers of patients with evaluable measurements for GH and IGF-1 are shown beneath each graph. Oct octreotide LAR; Pas pasireotide LAR arms, respectively); review of these cases revealed that the majority of patients who withdrew consent did so because they elected to undergo pituitary surgery. During the blinded extension phase, two $(2.7 \%)$ patients in the pasireotide LAR arm and one $(2.2 \%)$ patient in the octreotide LAR arm discontinued because of AEs; one of these patients, who was receiving pasireotide LAR, discontinued because of a serious AE. Two deaths occurred during the extension phase (major depression leading to suicide in a pasireotide LAR patient, sepsis in an octreotide LAR patient). Neither of the deaths were considered by the investigator to be related to study drug.

Most patients experienced at least one AE with a suspected relationship to study drug during the 26-month study period (86.5 and 77.2\% in the pasireotide LAR and octreotide LAR arms, respectively); most were mild to moderate in nature. The most common AEs were diarrhea and cholelithiasis (Table 3). Overall, 112 patients (62.9\%) in the pasireotide LAR arm experienced a hyperglycemiarelated AE (all terms relating to elevations in blood glucose, e.g. hyperglycemia, diabetes mellitus, etc.), compared with 45 patients $(25.0 \%)$ in the octreotide LAR arm. In total, $32(18.0 \%)$ and $27(15.0 \%)$ patients experienced at least one serious AE in the pasireotide LAR and octreotide LAR arms, respectively; $11(6.2 \%)$ and $11(6.1 \%)$ patients experienced at least one serious drug-related AE.

Mean glucose and $\mathrm{HbA}_{1 \mathrm{c}}$ increased in the first 3 months after initiation of pasireotide therapy and remained stable to 26 months (Fig. 4). For octreotide, a smaller and more gradual increase in mean glucose and $\mathrm{HbA}_{1 \mathrm{c}}$ was observed, which peaked at months 9-12 and remained relatively 
Table 3 Most common AEs ( $>10 \%$ in either treatment arm) reported during the 26-month study period, regardless of relationship to study drug

\begin{tabular}{|c|c|c|c|c|}
\hline & \multicolumn{2}{|c|}{$\begin{array}{l}\text { Pasireotide LAR } \\
\left(\mathrm{N}=178^{\mathrm{a}}\right)\end{array}$} & \multicolumn{2}{|c|}{$\begin{array}{l}\text { Octreotide LAR } \\
\left(\mathrm{N}=180^{\mathrm{a}}\right)\end{array}$} \\
\hline & $\begin{array}{l}\text { All } \\
\text { grades } \\
\text { n }(\%)\end{array}$ & $\begin{array}{l}\text { Grade } \\
3 / 4 \\
\mathrm{n}(\%)\end{array}$ & $\begin{array}{l}\text { All } \\
\text { grades } \\
\text { n }(\%)\end{array}$ & $\begin{array}{l}\text { Grade } \\
3 / 4 \\
\text { n }(\%)\end{array}$ \\
\hline Diarrhea & 71 (39.9) & $1(0.6)$ & $81(45.0)$ & $5(2.8)$ \\
\hline Hyperglycemia & $55(30.9)$ & $6(3.4)$ & $18(10.0)$ & $1(0.6)$ \\
\hline Cholelithiasis & $54(30.3)$ & $2(1.1)$ & $71(39.4)$ & $3(1.7)$ \\
\hline Headache & $40(22.5)$ & $2(1.1)$ & $49(27.2)$ & $5(2.8)$ \\
\hline Diabetes mellitus & $38(21.3)$ & $9(5.1)$ & $8(4.4)$ & 0 \\
\hline Alopecia & $34(19.1)$ & 0 & $36(20.0)$ & 0 \\
\hline Abdominal pain & $33(18.5)$ & $1(0.6)$ & $44(24.4)$ & 0 \\
\hline Nasopharyngitis & $31(17.4)$ & 0 & $29(16.1)$ & 0 \\
\hline Nausea & $27(15.2)$ & $1(0.6)$ & $41(22.8)$ & 0 \\
\hline $\begin{array}{l}\text { Increased blood creatine } \\
\text { phosphokinase }\end{array}$ & $25(14.0)$ & $6(3.4)$ & $24(13.3)$ & $4(2.2)$ \\
\hline Arthralgia & $21(11.8)$ & $1(0.6)$ & 25 (13.9) & $1(0.6)$ \\
\hline Back pain & $21(11.8)$ & 0 & $22(12.2)$ & $2(1.1)$ \\
\hline Abdominal distension & $21(11.8)$ & $1(0.6)$ & $22(12.2)$ & $1(0.6)$ \\
\hline Dizziness & $21(11.8)$ & 0 & $20(11.1)$ & 0 \\
\hline Fatigue & $19(10.7)$ & $1(0.6)$ & $21(11.7)$ & 0 \\
\hline Hypertension & $18(10.1)$ & $2(1.1)$ & $16(8.9)$ & $4(2.2)$ \\
\hline Constipation & $10(5.6)$ & 0 & 19 (10.6) & 0 \\
\hline
\end{tabular}

AEs are presented in overall descending order for the pasireotide LAR arm, starting with the most frequent

${ }^{a}$ Two patients randomized to the octreotide LAR treatment arm received pasireotide LAR in error. These two patients are included in the pasireotide LAR treatment arm for the purposes of the safety analysis

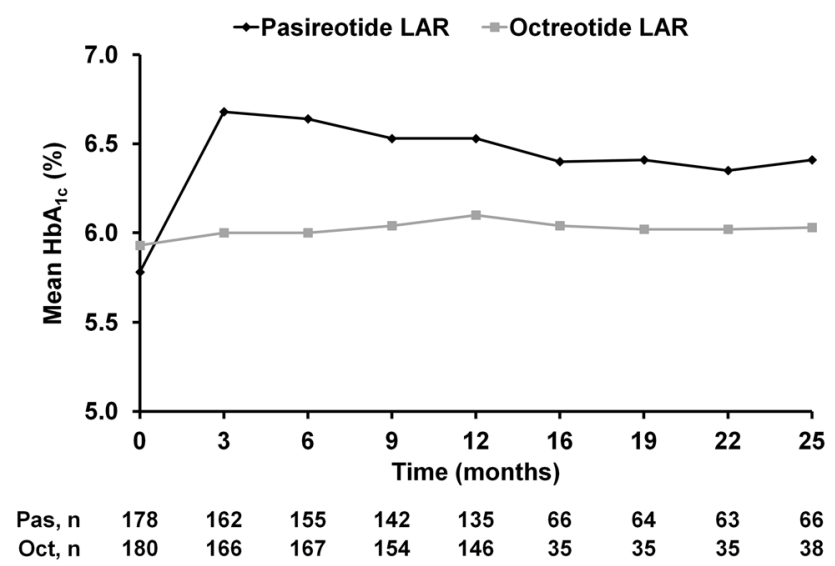

Fig. 4 Mean $\mathrm{HbA}_{1 \mathrm{c}}$ over time from core baseline up to month 25

stable up to month 26 . Of the 119 patients in the pasireotide LAR arm with normal fasting glucose $(<100 \mathrm{mg} / \mathrm{dL})$ at core baseline, $83(69.7 \%)$ experienced worsening of fasting glucose levels at last available assessment during the core or extension; 23/51 (45.1\%) patients who had core baseline levels of 100 to $<126 \mathrm{mg} / \mathrm{dL}$ had levels $\geq 126 \mathrm{mg} /$ $\mathrm{dL}$ at the last available assessment (Table 4). In the octreotide LAR arm, 43/109 (39.4\%) patients with normal baseline fasting glucose levels and 7/54 (13.0\%) patients with baseline levels of 100 to $<126 \mathrm{mg} / \mathrm{dL}$ had worse levels at the last available assessment.

At baseline, $41.6 \%(74 / 178)$ of patients in the pasireotide LAR arm had normal $\mathrm{HbA}_{1 \mathrm{c}}$ levels; $52.7 \%$ (39/74) and $23.0 \%(17 / 74)$ of these patients had last available $\mathrm{HbA}_{1 \mathrm{c}}$ levels in the pre-diabetic and diabetic ranges, respectively (Table 5). Overall, $58.4 \%$ (104/178) of patients in the pasireotide LAR arm had a last available $\mathrm{HbA}_{1 \mathrm{c}}$ level indicating a worse diabetic status than at core baseline. Sixty-six patients in the octreotide LAR arm had normal $\mathrm{HbA}_{1 \mathrm{c}}$ levels at baseline. Of these patients, 32 $(48.5 \%)$ and two $(3.0 \%)$ had last available $\mathrm{HbA}_{1 \mathrm{c}}$ levels in the pre-diabetic and diabetic ranges, respectively. Overall, $28.3 \%$ (51/180) of patients in the octreotide LAR arm had a last available $\mathrm{HbA}_{1 \mathrm{c}}$ level indicating a worse diabetic status than at core baseline.

In total, $85(47.8 \%)$ pasireotide LAR patients and 48 (26.7\%) octreotide LAR patients received concomitant anti-diabetic medication during the 26-month study period; metformin was most commonly used. Of the patients who were not receiving anti-diabetic medication at core baseline, at least one anti-diabetic medication was initiated in $40.4 \%(63 / 156)$ of patients in the pasireotide LAR arm and $5.7 \%(8 / 140)$ of patients in the octreotide LAR arm.

\section{Discussion}

This report from the extension phase of a large Phase III study is the first long-term analysis of pasireotide LAR in medically naïve patients (42\% post-surgical and $58 \%$ de novo at core baseline) with acromegaly. It demonstrates that GH and IGF-1 suppression is maintained in patients who continue receiving pasireotide LAR and octreotide LAR for up to 25 months and that long-term treatment is generally well tolerated. Importantly, median GH levels were $<2.5 \mu \mathrm{g} / \mathrm{L}$ and IGF-1 levels were maintained below the ULN for up to 25 months in both treatment arms. In addition to effects on GH and IGF-1, both pasireotide LAR and octreotide LAR provided overall clinical benefit by effectively improving the signs and symptoms of acromegaly and reducing tumor volume. These results are in line with those of previous long-term studies of somatostatin analogues in acromegaly [8-13]; however, few have evaluated a combined clinical endpoint of both $\mathrm{GH}<2.5 \mu \mathrm{g} / \mathrm{L}$ and normalization of IGF-1.

Patients were eligible to enter the extension study if they had achieved biochemical control in the 12-month core 
Table 4 Overall shift in glucose from core baseline to last available value up to month 26

\begin{tabular}{|c|c|c|c|c|c|}
\hline & \multirow{2}{*}{$\begin{array}{l}\text { Extension baseline } \\
\mathrm{n}(\%)\end{array}$} & \multicolumn{4}{|c|}{ Last reported value } \\
\hline & & $\begin{array}{l}<100 \mathrm{mg} / \mathrm{dL} \\
\mathrm{n}(\%)\end{array}$ & $\begin{array}{l}100 \text { to }<126 \mathrm{mg} / \mathrm{dL} \\
\mathrm{n}(\%)\end{array}$ & $\begin{array}{l}\geq 126 \mathrm{mg} / \mathrm{dL} \\
\mathrm{n}(\%)\end{array}$ & $\begin{array}{l}\text { Missing } \\
\mathrm{n}(\%)\end{array}$ \\
\hline \multicolumn{6}{|c|}{ Pasireotide LAR $(\mathrm{N}=178)$} \\
\hline$<100 \mathrm{mg} / \mathrm{dL}$ & $119(66.9)$ & $35(19.7)$ & $60(33.7)$ & $23(12.9)$ & $1(0.6)$ \\
\hline 100 to $<126 \mathrm{mg} / \mathrm{dL}$ & $51(28.7)$ & $10(5.6)$ & $18(10.1)$ & $23(12.9)$ & 0 \\
\hline$\geq 126 \mathrm{mg} / \mathrm{dL}$ & $7(3.9)$ & 0 & $3(1.7)$ & $4(2.2)$ & 0 \\
\hline Missing & $1(0.6)$ & $1(0.6)$ & 0 & 0 & 0 \\
\hline Total & $178(100.0)$ & $46(25.8)$ & $81(45.5)$ & $50(28.1)$ & $1(0.6)$ \\
\hline \multicolumn{6}{|c|}{ Octreotide LAR $(\mathrm{N}=180)$} \\
\hline$<100 \mathrm{mg} / \mathrm{dL}$ & $109(60.6)$ & $66(36.7)$ & $40(22.2)$ & $3(1.7)$ & 0 \\
\hline 100 to $<126 \mathrm{mg} / \mathrm{dL}$ & $54(30.0)$ & $17(9.4)$ & $30(16.7)$ & $7(3.9)$ & 0 \\
\hline$\geq 126 \mathrm{mg} / \mathrm{dL}$ & $17(9.4)$ & $2(1.1)$ & $7(3.9)$ & $8(4.4)$ & 0 \\
\hline Missing & 0 & 0 & 0 & 0 & 0 \\
\hline Total & $180(100)$ & $85(47.2)$ & $77(42.8)$ & $18(10.0)$ & 0 \\
\hline
\end{tabular}

Shaded boxes represent the patients with a shift in glucose level $(\mathrm{mg} / \mathrm{dL})$ that indicates a worse diabetic status at the last reported value compared with core baseline

Table 5 Overall shift in $\mathrm{HbA}_{1 \mathrm{c}}$ from core baseline to last available value up to month 26

\begin{tabular}{|c|c|c|c|c|c|c|}
\hline & \multirow{2}{*}{$\begin{array}{l}\text { Extension baseline } \\
\mathrm{n}(\%)\end{array}$} & \multicolumn{5}{|c|}{ Last reported value } \\
\hline & & $\begin{array}{l}<5.7 \% \\
\mathrm{n}(\%)\end{array}$ & $\begin{array}{l}5.7 \text { to }<6.5 \% \\
\mathrm{n}(\%)\end{array}$ & $\begin{array}{l}6.5 \text { to }<8 \% \\
\mathrm{n}(\%)\end{array}$ & $\begin{array}{l}\geq 8 \% \\
\mathrm{n}(\%)\end{array}$ & $\begin{array}{l}\text { Missing } \\
\mathrm{n}(\%)\end{array}$ \\
\hline \multicolumn{7}{|c|}{ Pasireotide LAR $(\mathrm{N}=178)$} \\
\hline$<5.7 \%$ & $74(41.6)$ & $17(9.6)$ & $39(21.9)$ & $13(7.3)$ & $4(2.2)$ & $1(0.6)$ \\
\hline 5.7 to $<6.5 \%$ & $87(48.9)$ & $4(2.2)$ & $35(19.7)$ & $42(23.6)$ & $6(3.4)$ & 0 \\
\hline 6.5 to $<8 \%$ & $17(9.6)$ & $1(0.6)$ & $2(1.1)$ & $9(5.1)$ & $5(2.8)$ & 0 \\
\hline$\geq 8 \%$ & 0 & 0 & 0 & 0 & 0 & 0 \\
\hline Missing & 0 & 0 & 0 & 0 & 0 & 0 \\
\hline Total & $178(100.0)$ & $22(12.4)$ & $76(42.7)$ & $64(36.0)$ & $15(8.4)$ & $1(0.6)$ \\
\hline \multicolumn{7}{|c|}{ Octreotide LAR $(\mathrm{N}=180)$} \\
\hline$<5.7 \%$ & $66(36.7)$ & $31(17.2)$ & $32(17.8)$ & $2(1.1)$ & 0 & $1(0.6)$ \\
\hline 5.7 to $<6.5 \%$ & $82(45.6)$ & $7(3.9)$ & $57(31.7)$ & $15(8.3)$ & $2(1.1)$ & $1(0.6)$ \\
\hline 6.5 to $<8 \%$ & $30(16.7)$ & $1(0.6)$ & $13(7.2)$ & $12(6.7)$ & $3(1.7)$ & $1(0.6)$ \\
\hline$\geq 8 \%$ & $2(1.1)$ & 0 & 0 & $1(0.6)$ & $1(0.6)$ & 0 \\
\hline Missing & 0 & 0 & 0 & 0 & 0 & 0 \\
\hline Total & $180(100)$ & $39(21.7)$ & $102(56.7)$ & $30(16.7)$ & $6(3.3)$ & $3(1.7)$ \\
\hline
\end{tabular}

Shaded boxes represent the patients with a shift in $\mathrm{HbA}_{1 \mathrm{c}}$ level (\%) that indicates a worse diabetic status at the last reported value compared with core baseline

study, or if the investigator judged that they were receiving clinical benefit from treatment (irrespective of biochemical control). Fewer patients in the octreotide LAR arm were eligible to continue on their randomized therapy in the extension phase compared with the pasireotide LAR arm ( 25.3 versus $42.0 \%$ of patients, respectively). This is in 
line with the core study data showing that pasireotide LAR was significantly superior to octreotide LAR at providing $\mathrm{GH}<2.5 \mu \mathrm{g} / \mathrm{L}$ and normal IGF-1 [16], even after accounting for the fact that four patients could not continue receiving octreotide LAR in the extension phase as they entered the study before the protocol amendment was implemented. As the extension phase was not designed or powered to compare pasireotide LAR with octreotide LAR, no conclusions can be drawn regarding the relative efficacy of these somatostatin analogues over the 25-month treatment period. In addition, because all patients entering the extension were benefiting from their randomized treatment, no difference between the treatment arms would be expected.

At the beginning of the extension phase, $71.6 \%$ of patients in the pasireotide LAR arm and $56.5 \%$ in the octreotide LAR arm had $\mathrm{GH}<2.5 \mu \mathrm{g} / \mathrm{L}$ and IGF$1 \leq 1 \times$ ULN. After 25 months of treatment, the proportions were 60.8 and $52.2 \%$, respectively. The most common reason for discontinuation in both treatment arms during the blinded extension phase was consent withdrawal; the majority of these patients elected to undergo pituitary surgery.

During the blinded extension phase, the safety profile of pasireotide LAR was similar to that of octreotide LAR, except for the frequency and degree of hyperglycemia. The safety profiles of pasireotide LAR and octreotide LAR during the blinded extension phase were similar to those seen in the 12-month core study. However, although $\mathrm{HbA}_{1 \mathrm{c}}$ and glucose levels initially increased in the first 3 months of pasireotide treatment, they then remained stable to 26 months. The administration of anti-diabetic medication, most commonly metformin, may have contributed to the lack of further deterioration in glucose homeostasis with pasireotide LAR; almost half of patients receiving pasireotide LAR received an anti-diabetic agent during the 26-month study, while $\geq 1$ agent was initiated in $40.4 \%$ of patients who were not receiving medication at baseline. As changes in the dose of concomitant medications were not recorded during the 26 months of treatment, further studies are necessary to determine the effects of anti-diabetic therapies on the stabilization of $\mathrm{HbA}_{1 \mathrm{c}}$ and glucose levels during pasireotide treatment. As sst $_{5}$ receptors are expressed on tissues such as pancreatic islet cells [19], the higher levels of hyperglycemia observed with pasireotide may be a result of its higher binding affinity for sst $_{5}$ compared with other somatostatin analogues. A recent study in healthy volunteers has shown that although pasireotide inhibits insulin secretion and incretin response, with modest suppression of glucagon, it does not affect insulin sensitivity [20]. After initiation of pasireotide, all patients should be closely monitored for changes in glucose homeostasis; in the event of hyperglycemia, prompt intervention is warranted. Importantly, no new safety signals were identified in the extension phase that would caution against long-term use of pasireotide LAR.

In conclusion, pasireotide LAR and octreotide LAR provide long-term inhibition of GH and IGF-1 in patients with acromegaly. Therefore, pasireotide LAR is a viable new treatment option for patients with acromegaly.

Acknowledgments We thank all the investigators who contributed to the study, as well as the study nurses and coordinators and the patients who participated in the study. This study was funded by Novartis Pharma AG. Financial support for medical editorial assistance was provided by Novartis Pharmaceuticals Corporation. We thank Andrew Jones, PhD for medical editorial assistance with this manuscript.

Ethical standards The study was conducted in accordance with the Declaration of Helsinki and complies with the current laws of the countries in which it was performed. An independent ethics committee or institutional review board for each study site approved the study protocol. All patients provided written informed consent to participate in the trial.

Conflict of interest MS has received speaker fees from Novartis. MDB has received consulting fees, speaker fees, and research grants from Novartis and is a principal investigator of clinical trials supported by Novartis. PF, OS, and LN have received research grants from Novartis. LR has received lecture fees from Novartis. AC has received research grants and lecture fees from Novartis. MR, KHR, and YC are employed by Novartis. LDM has no financial relationship with Novartis.

Open Access This article is distributed under the terms of the Creative Commons Attribution License which permits any use, distribution, and reproduction in any medium, provided the original author(s) and the source are credited.

\section{References}

1. Ayuk J, Sheppard MC (2008) Does acromegaly enhance mortality? Rev Endocr Metab Disord 9:33-39

2. Holdaway IM, Rajasoorya RC, Gamble GD (2004) Factors influencing mortality in acromegaly. J Clin Endocrinol Metab 89:667-674

3. Holdaway IM, Bolland MJ, Gamble GD (2008) A meta-analysis of the effect of lowering serum levels of GH and IGF-I on mortality in acromegaly. Eur J Endocrinol 159:89-95

4. Colao A, Ferone D, Marzullo P, Lombardi G (2004) Systemic complications of acromegaly: epidemiology, pathogenesis, and management. Endocr Rev 25:102-152

5. Melmed S, Colao A, Barkan A, Molitch M, Grossman AB, Kleinberg D, Clemmons D, Chanson P, Laws E, Schlechte J, Vance ML, Ho K, Giustina A (2009) Guidelines for acromegaly management: an update. J Clin Endocrinol Metab 94:1509-1517

6. Katznelson L, Atkinson JL, Cook DM, Ezzat SZ, Hamrahian AH, Miller KK (2011) American Association of Clinical Endocrinologists medical guidelines for clinical practice for the diagnosis and treatment of acromegaly: 2011 update: executive summary. Endocr Pract 17:636-646

7. Colao A, Martino E, Cappabianca P, Cozzi R, Scanarini M, Ghigo E (2006) First-line therapy of acromegaly: a statement of the A.L.I.C.E. (Acromegaly primary medical treatment Learning 
and Improvement with Continuous medical Education) study group. J Endocrinol Invest 29:1017-1020

8. Ayuk J, Stewart SE, Stewart PM, Sheppard MC (2002) Longterm safety and efficacy of depot long-acting somatostatin ana$\log$ for the treatment of acromegaly. J Clin Endocrinol Metab 87:4142-4146

9. Colao A, Ferone D, Marzullo P, Cappabianca P, Cirillo S, Boerlin V, Lancranjan I, Lombardi G (2001) Long-term effects of depot long-acting somatostatin analog octreotide on hormone levels and tumor mass in acromegaly. J Clin Endocrinol Metab 86:2779-2786

10. Cozzi R, Montini M, Attanasio R, Albizzi M, Lasio G, Lodrini S, Doneda P, Cortesi L, Pagani G (2006) Primary treatment of acromegaly with octreotide LAR: a long-term (up to 9 years) prospective study of its efficacy in the control of disease activity and tumor shrinkage. J Clin Endocrinol Metab 91:1397-1403

11. Maiza JC, Vezzosi D, Matta M, Donadille F, Loubes-Lacroix F, Cournot M, Bennet A, Caron P (2007) Long-term (up to 18 years) effects on GH/IGF-1 hypersecretion and tumour size of primary somatostatin analogue (SSTa) therapy in patients with GH-secreting pituitary adenoma responsive to SSTa. Clin Endocrinol (Oxf) 67:282-289

12. Colao A, Auriemma RS, Galdiero M, Lombardi G, Pivonello R (2009) Effects of initial therapy for five years with somatostatin analogs for acromegaly on growth hormone and insulin-like growth factor-I levels, tumor shrinkage, and cardiovascular disease: a prospective study. J Clin Endocrinol Metab 94:3746-3756

13. Amato G, Mazziotti G, Rotondi M, Iorio S, Doga M, Sorvillo F, Manganella G, Di Salle F, Giustina A, Carella C (2002) Longterm effects of lanreotide SR and octreotide $\mathrm{LAR}^{\circledR}$ on tumour shrinkage and GH hypersecretion in patients with previously untreated acromegaly. Clin Endocrinol (Oxf) 56:65-71
14. Colao A, Auriemma RS, Lombardi G, Pivonello R (2011) Resistance to somatostatin analogs in acromegaly. Endocr Rev 32:247-271

15. Bruns C, Lewis I, Briner U, Meno-Tetang G, Weckbecker G (2002) SOM230: a novel somatostatin peptidomimetic with broad somatotropin release inhibiting factor (SRIF) receptor binding and a unique antisecretory profile. Eur J Endocrinol 146:707-716

16. Colao A, Bronstein MD, Freda P, Gu F, Shen C-C, Gadelha M, Fleseriu M, van der Lely AJ, Farrall AJ, Hermosillo Reséndiz K, Ruffin M, Chen Y, Sheppard M (2014) Pasireotide versus octreotide in acromegaly: a head-to-head superiority study. J Clin Endocrinol Metab 99:791-799

17. Petersenn S, Schopohl J, Barkan A, Mohideen P, Colao A, Abs R, Buchelt A, Ho Y-Y, Hu K, Farrall AJ, Melmed S, Biller BM (2010) Pasireotide (SOM230) demonstrates efficacy and safety in patients with acromegaly: a randomized, multicenter, Phase II trial. J Clin Endocrinol Metab 95:2781-2789

18. National Cancer Institute. Common Terminology Criteria for Adverse Events v3.0 (CTCAE). 2006. Available at: http://ctep. cancer.gov/protocolDevelopment/electronic_applications/docs/ ctcaev3.pdf

19. Kumar U, Sasi R, Suresh S, Patel A, Thangaraju M, Metrakos P, Patel SC, Patel YC (1999) Subtype-selective expression of the five somatostatin receptors (hSSTR1-5) in human pancreatic islet cells: a quantitative double-label immunohistochemical analysis. Diabetes 48:77-85

20. Henry RR, Ciaraldi TP, Armstrong D, Burke P, Ligueros-Saylan M, Mudaliar S (2013) Hyperglycemia associated with pasireotide: results from a mechanistic study in healthy volunteers. J Clin Endocrinol Metab 98:3446-3453 